\title{
Ráfagas de aire, formas de habitar los sitios de memoria. Muestra de fotografías en el Museo de Arte y Memoria (MAM) de La Plata
}

\author{
Melina Jean Jean \\ Instituto de Investigaciones en Humanidades y Ciencias Sociales (IdIHCS, UNLP/CONICET), Argentina \\ melinajeanjean@gmail.com \\ Florencia Basso \\ Instituto de Investigación en Producción y Enseñanza del Arte Argentino y Latinoamericano (UNLP), Argentina \\ florenciabasso@gmail.com
}

El 29 de junio de 2011 se sancionó en Argentina la Ley Nacional 26.691 que declara Sitios de Memoria a los lugares que funcionaron como centros clandestinos de detención, tortura y exterminio (CCDTyE) o donde sucedieron hechos emblemáticos del accionar de la represión ilegal desarrollada durante el terrorismo de Estado ejercido en el país hasta el 10 de diciembre de 1983. Como autoridad de aplicación, la Secretaría de Derechos Humanos de la Nación a través de la Dirección Nacional de Sitios de Memoria reglamentó la Ley en el 2014 y se comprometió a garantizar la preservación, señalización y difusión de los sitios, así como también su gestión, y la promoción y asistencia de proyectos de nuevos espacios de memoria. De esta forma, se consolidó el trabajo interjurisdiccional que se venía desarrollando desde la Red Federal de Sitios de Memoria, creada en el 2006 en la órbita del Archivo Nacional de la Memoria.

La creación de espacios de memorias en los ex CCDTyE supuso un gran desafío: por un lado, en cuanto a las cualidades que adquieren como sitios de valor testimonial y su aporte a investigaciones judiciales relacionadas con los crímenes de lesa humanidad; y por otro lado, sobre la propia transformación del sitio que supone diálogos, tensiones, disputas y consensos entre todos los agentes intervinientes en su gestión. Esto además involucra la planificación de actividades educativas y de investigación que pretenden como objetivo principal difundir los hechos allí acaecidos (también a nivel nacional) y sostener la defensa irrestricta de los derechos humanos.

"Ráfagas de aire, formas de habitar los sitios de memoria" es una muestra de fotografías curada por Cora Gamarnik y Florencia Larralde Armas -producida con el financiamiento del Fondo Nacional de las Artes y el apoyo de la Comisión Provincial por la Memoria- expuesta en el Museo de Arte y Memoria (MAM) de La Plata durante el mes de julio de 2019, que precisamente relata de manera visual esta compleja reconversión de los sitios a espacios de memoria. Se trata de registros provenientes de los 34 espacios de memoria que funcionan en todo el país (se estiman más de 600 CCDTyE de los cuales ya fueron señalizados 106) y nos muestran/enseñan los diversos modos en que fueron habitados, transformados, subvertidos.

$\mathrm{Al}$ recorrer las salas y observar detenidamente las fotografías expuestas y seleccionadas para esta ocasión, se percibe una intencionalidad curatorial de generar un corrimiento de la mirada, un énfasis puesto no tanto en la arquitectura del sitio -como algo dado, estable y fijo- sino, más bien, sobre aquella arquitectura más efímera, esa práctica nueva artística, pedagógica y/o ritual que pone a dialogar y reinventar el sitio. No sólo se evita, de esta manera, reificar o encapsular la memoria, sino que se apuesta al acto de retomar el pasado, aquella ráfaga de aire, aquél "recuerdo que relampaguea en el instante de un peligro" (Benjamin citado en Löwy, 2012), para reflexionar sobre el presente y futuro, y poder repensar las memorias desde una mirada (re)politizada. 
El recorrido por las imágenes de la exposición, entonces, nos despierta y estimula a tener estas otras miradas, miradas oblicuas, sobre los sitios de memoria. No sólo por la descentralización de los lugares que aparecen -centros de memoria ubicados geográficamente en distintos puntos del país como el Chaco, Santa Fé, Tucumán, Chubut, Río Negro, Córdoba, Mendoza-. Sino también por la amplitud temática que incluye la selección propuesta: por un lado, Sitios de Memoria del terrorismo de Estado de la última dictadura cívico-militar argentina y por otro lado, producciones estéticas sobre la memoria mapuche o manifestaciones por la legalización del aborto. A esto se suman las apropiaciones que las generaciones más jóvenes hacen de esos lugares y la variedad de prácticas que actualizan los rituales y la estética de la memoria en tanto conmemoraciones, manifestaciones, inauguraciones, intervenciones artísticas, señalizaciones, siluetazos, "encendidos", proyecciones y mapeos, pintadas, suelta de globos y recitales.

En este mismo sentido, la dimensión pedagógica está muy presente en las experiencias capturadas fotográficamente, destacando la labor que hacen distintos educadores en torno a las memorias de los sitios. Múltiples manifestaciones didácticas se hacen presentes -talleres educativos, artísticos, recorridos de grupos escolares, encuentros de jóvenes, producción de herramientas y recursos pedagógicos diversos- destacando la importancia de reflexionar con las nuevas generaciones sobre el pasado. Lo que en definitiva puede responder al para qué de los Sitios de Memoria, reafirmando su valor para la elaboración de nuestro pasado reciente y su importancia para los trabajos de memorias que desde el presente buscan ejemplarizar y darle cuerpo al nunca más. Así lo describe una impactante imagen capturada por Carlos Cáceres en la que vemos un lienzo alzado por encima de una multitud que versa: "Si no existe la memoria todo lo nuestro es suicida".

La imbricación de espacios y, fundamentalmente, de tiempos en cada una de estas fotografías, nos pone de manifiesto la complejidad y la porosidad presentes en la construcción de memorias. El dispositivo fotográfico, en este sentido, es clave para transmitir la fragmentariedad del pasado: no sólo se manifiestan los momentos del horror en los sitios retratados y su transformación en Sitios de Memoria, sino que también aparecen tanto las actualizaciones en sus rituales y usos diversos -conmemoraciones, recitales, recorridos, etc.- como el tiempo de la expectación de la exposición por parte del visitante y la convivencia entre esas fotografías: a modo de sutiles reflejos espejados, nos vemos a nosotrxs y a las otras fotografías dentro de la imagen que observamos.

Reflejos sobre el soporte de la fotografía de Victoria Gesualdi en el Parque de la Memoria, Buenos Aires.

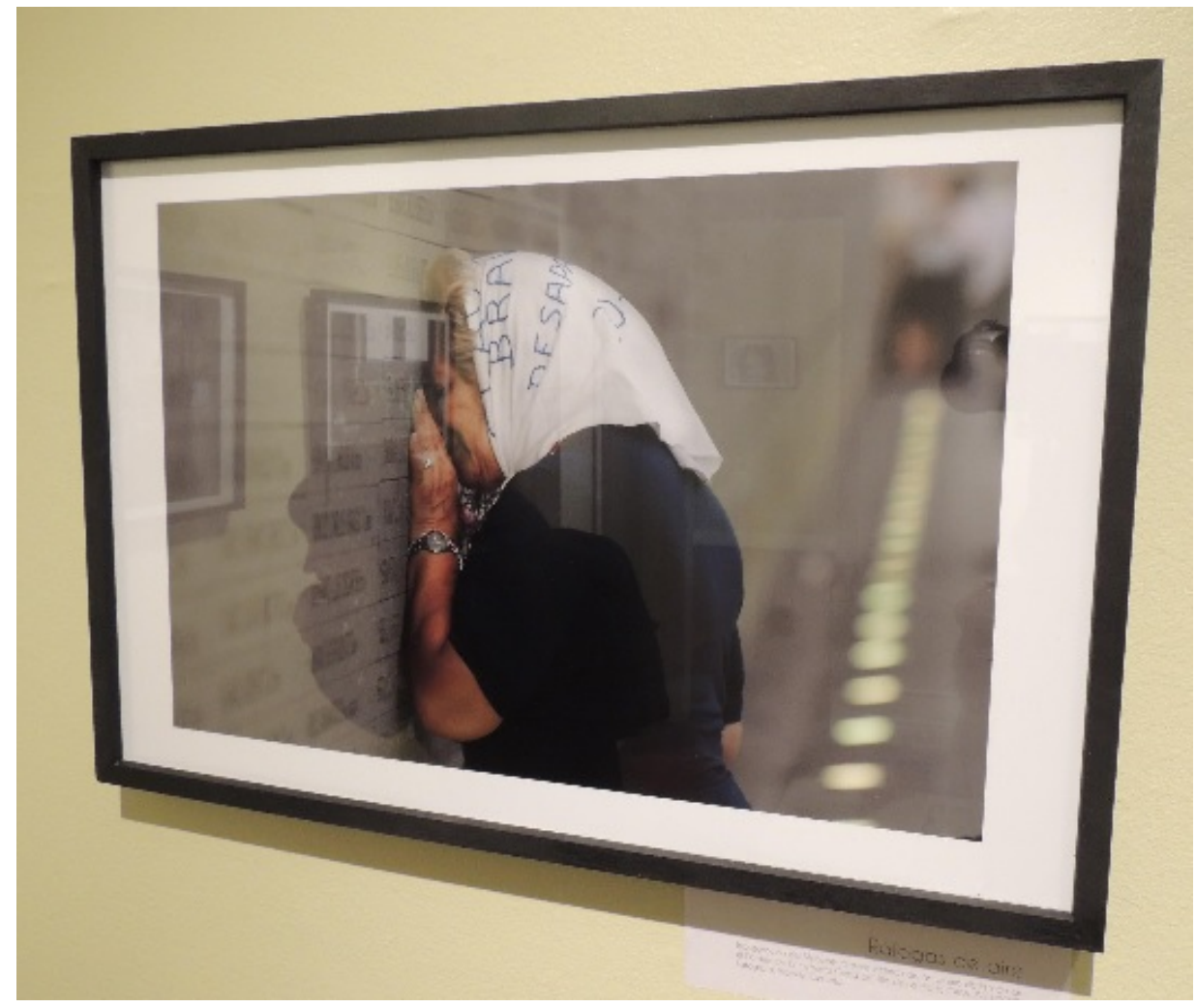

Fuente: Melina Jean Jean 
Para conocer la Muestra les invitamos a visitar la Galería realizada por la Comisión Provincial de la Memoria en su sitio web: https://www.comisionporlamemoria.org/investigacion/rafagas-de-aire/

A continuación, unas fotografías tomadas por el equipo de la CPM el día de la inauguración de la muestra en el MAM:
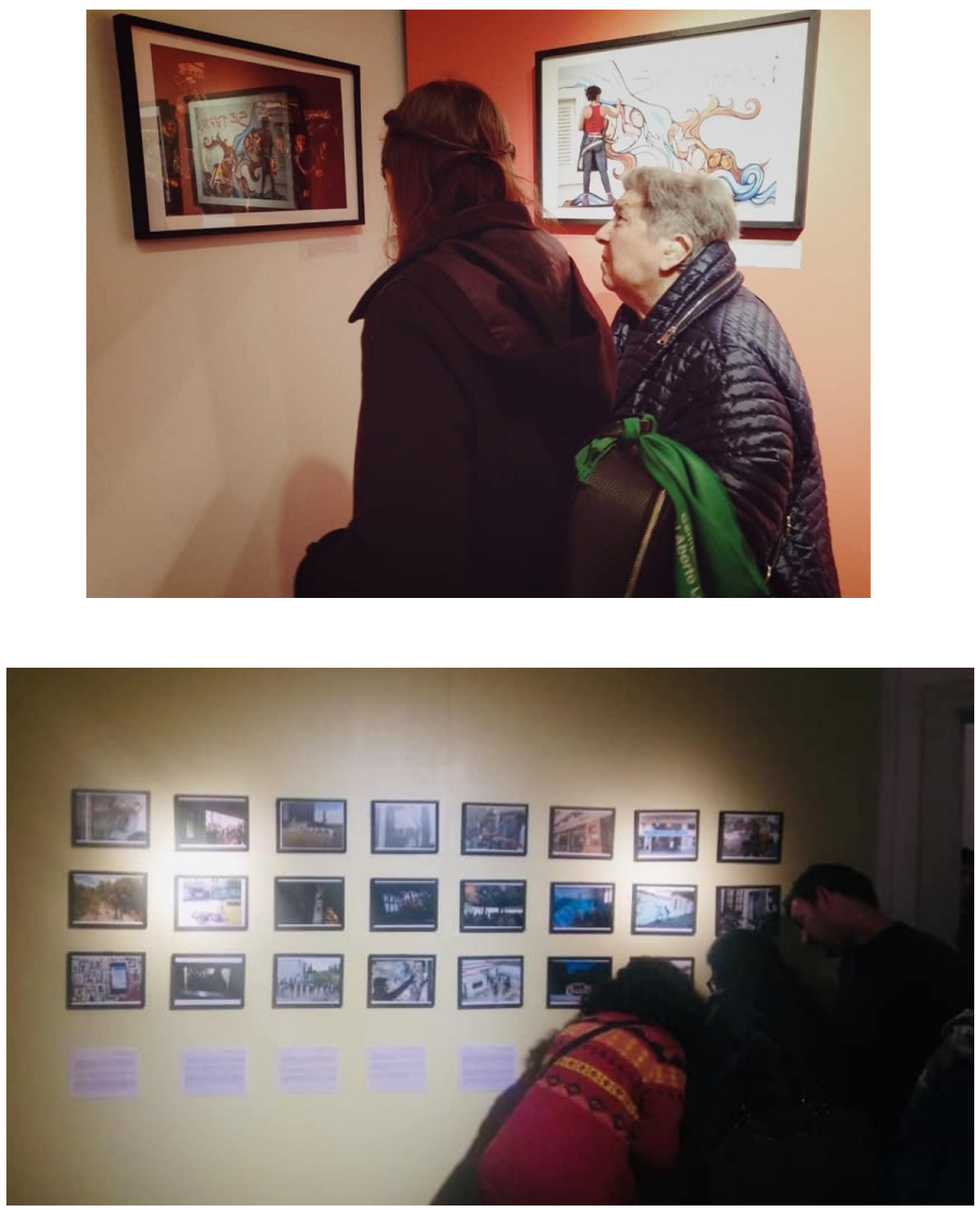

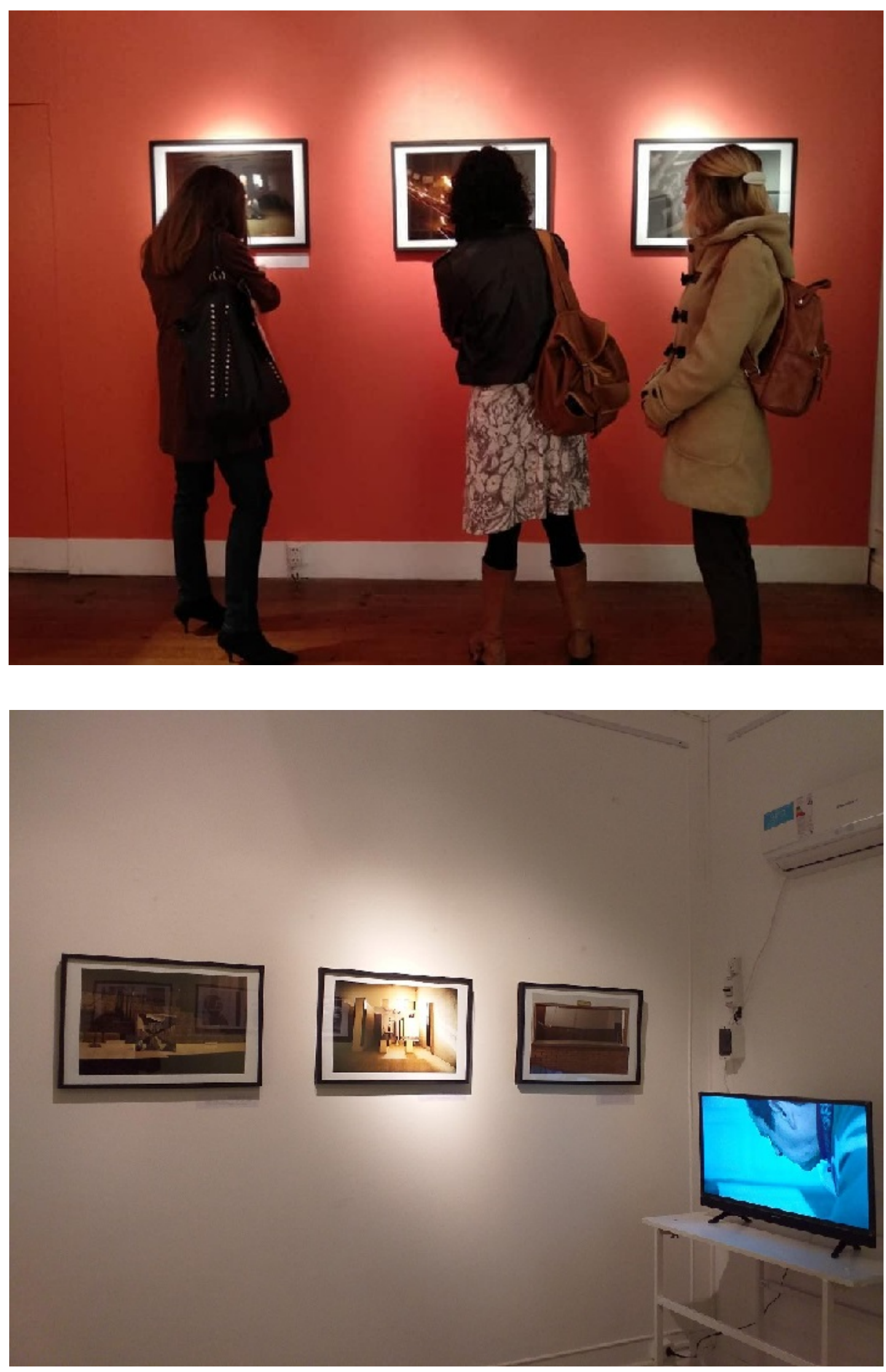


\section{REFERENCIAS}

Löwy, M. (2012). Walter Benjamin: aviso de incendio. Una lectura de las tesis "sobre el concepto de historia". Buenos Aires: Fondo de Cultura Económica.

Argentina. Ministerio de Justicia y Derechos Humanos, Presidencia de la Nación (2011) DERECHOS HUMANOS. Ley 26.691. Recuperado de: http://servicios.infoleg.gob.ar/infolegInternet/anexos/180000-184999/184962/n orma.htm

Argentina. Ministerio de Justicia y Derechos Humanos, Secretaría de Derechos Humanos, Archivo Nacional de la Memoria. Sitios de Memoria. Recuperado de: https://www.argentina.gob.ar/derechoshumanos/sitiosdememor ia 